\title{
Reviews
}

\section{Hypoglycaemia: The limiting factor in the glycaemic management of Type I and Type II Diabetes*}

\author{
P. E. Cryer \\ Division of Endocrinology, Diabetes and Metabolism, and the General Clinical Research Center and the Diabetes Research \\ and Training Center, Washington University School of Medicine, St. Louis, Missouri, USA
}

\begin{abstract}
Hypoglycaemia is the limiting factor in the glycaemic management of diabetes. Iatrogenic hypoglycaemia is typically the result of the interplay of insulin excess and compromised glucose counterregulation in Type I (insulin-dependent) diabetes mellitus. Insulin concentrations do not decrease and glucagon and epinephrine concentrations do not increase normally as glucose concentrations decrease. The concept of hypoglycaemia-associated autonomic failure (HAAF) in Type I diabetes posits that recent antecedent iatrogenic hypoglycaemia causes both defective glucose counterregulation (by reducing the epinephrine response in the setting of an absent glucagon response) and hypoglycaemia unawareness (by reducing the autonomic and the resulting neurogenic symptom responses). Perhaps the most compelling support for HAAF is the finding that as little as 2 to 3 weeks of scrupulous avoidance of hypoglycaemia reverses hypoglycaemia unawareness and improves the reduced epinephrine component of defective glucose counterregulation in most affected patients. The mediator and mechanism
\end{abstract}

of HAAF are not known but are under active investigation. The glucagon response to hypoglycaemia is also reduced in patients approaching the insulin deficient end of the spectrum of Type II (non-insulin-dependent) diabetes mellitus, and glycaemic thresholds for autonomic (including epinephrine) and symptomatic responses to hypoglycaemia are shifted to lower plasma glucose concentrations after hypoglycaemia in Type II diabetes. Thus, patients with advanced Type II diabetes are also at risk for HAAF. While it is possible to minimise the risk of hypoglycaemia by reducing risks - including a 2 to 3 week period of scrupulous avoidance of hypoglycaemia in patients with hypoglycaemia unawareness - methods that provide glucose-regulated insulin replacement or secretion are needed to eliminate hypoglycaemia and maintain euglycaemia over a lifetime of diabetes. [Diabetologia (2002) 45:937-948]

Keywords Hypoglycaemia, glucagon, epinephrine, adrenal medulla, sympathetic nervous system, hypoglycaemia-associated autonomic failure.
Received: 3 September 2001 / Revised: 11 December 2001

Published online: 26 April 2002

(C) Springer-Verlag 2002

*The 2001 Claude Bernard Lecture of the European Association for the Study of Diabetes presented on 13 September 2001

Corresponding author: P. E. Cryer, MD, Division of Endocrinology, Diabetes and Metabolism, Washington University School of Medicine (Campus Box 8127), 660 South Euclid Avenue, St. Louis, MO 63110, USA, E-mail: pcryer@im.wustl. edu

Abbreviations: HAAF, Hypoglycaemia-associated autonomic failure; DCCT, diabetes control and complications trial; UKPDS, United Kingdom prospective diabetes study.

\section{The Barrier of Hypoglycaemia}

If it was not for the barrier of hypoglycaemia, people with diabetes mellitus could have normal $\mathrm{HbA}_{1 \mathrm{C}}$ values throughout a lifetime of diabetes.

Glycaemic control makes a difference for people with diabetes. Reduction of mean glycaemia prevents or delays microvascular complications - retinopathy, nephropathy and neuropathy - in both Type I (insulindependent) diabetes mellitus [1] and Type II (non-insulin-dependent) diabetes mellitus [2]. It could also reduce macrovascular events $[1,2]$. However, iatro- 
genic hypoglycaemia which is the result of the interplay of absolute or relative insulin excess and compromised glucose counterregulation in Type I diabetes [3, $4,5]$ is the limiting factor in the glycaemic management of diabetes. If it was not for the potentially devastating effects of hypoglycaemia on the brain, diabetes would be relatively easy to treat. Enough insulin, or any effective drug, to lower plasma glucose concentrations to or below the normal range would eliminate the symptoms of hyperglycaemia, prevent the acute hyperglycaemic complications (ketoacidosis, hyperosmolar syndrome), almost assuredly prevent the long-term microvascular complications $[1,2]$ and probably reduce macrovascular risk to baseline $[6,7]$. But, the effects of hypoglycaemia on the brain are real and the glycaemic management of diabetes is therefore complex and generally only partially successful.

Iatrogenic hypoglycaemia often causes recurrent physical and psychosocial morbidity and sometimes causes death [4]. Furthermore, it precludes true glycaemic control, ie. maintenance of euglycaemia over time, in the vast majority of people with diabetes $[1$, 2]. As a result, complications can develop or progress despite aggressive therapy. For example, in the Diabetes Control and Complications Trial (DCCT) in Type I diabetes, retinopathy developed or progressed in $14 \%$ of the patients treated intensively (compared with $32 \%$ of those treated conventionally) [1]. Similarly, in the United Kingdom Prospective Diabetes Study (UKPDS) in Type II diabetes any studied microvascular endpoint was reached in $8 \%$ of the patients treated intensively (compared with $11 \%$ of those treated less intensively) [2].

The barrier of iatrogenic hypoglycaemia could explain why aggressive attempts to achieve glycaemic control have had little impact on macrovascular events in people with diabetes $[1,2]$. It seems that the curve describing the relation between mean glycaemia (haemoglobin $A_{1 C}$ ) and macrovascular events, such as myocardial infarction, is shifted toward lower mean glycaemia compared with that between mean glycaemia and microvascular complications [6]. Indeed, there is evidence of an increased risk of death from ischemic heart disease in people with glycated haemoglobin concentrations in the high normal range [7]. Thus, while it is possible to reduce mean glycaemia enough to decrease the incidence of microvascular complications $[1,2]$, perhaps it is not practical, with current treatment regimens, to hold plasma glucose concentrations low enough and long enough to prevent macrovascular disease in a substantial proportion of people with diabetes because of the barrier of hypoglycaemia.

In short, we have a demonstrably effective glucoselowering drug. Given in sufficient doses insulin will lower plasma glucose concentrations, but we cannot replace insulin in a physiological fashion with current available methods. The temporal profile of the glucose-lowering actions of exogenous insulin adminis- tered to patients with diabetes (even the most rapidacting insulin analogues) is measured in hours while that of physiological endogenous insulin secretion by people without diabetes is measured in minutes. As a result, patients with diabetes given insulin doses sufficient to hold plasma glucose concentrations at non-diabetic levels part of the time are likely to suffer hypoglycaemia at other times, particularly when physiological defences against falling plasma glucose concentrations are compromised.

\section{Pathophysiology of Glucose Counterregulation in Type I diabetes}

Frequency of iatrogenic hypoglycaemia. Hypoglycaemia is a fact of life for people with Type I diabetes [4]; those attempting to achieve glycaemic control suffer many episodes of asymptomatic hypoglycaemia; glucose concentrations have been reported to be less than $3.3 \mathrm{mmol} / \mathrm{l}(60 \mathrm{mg} / \mathrm{dl}) 10 \%$ of the time $[4,8$, 9]. They suffer an average of two episodes of symptomatic hypoglycaemia a week - thousands of such episodes over a lifetime of diabetes - and an episode of severe, at least temporarily disabling, hypoglycaemia approximately once a year $[1,10,11]$. Indeed, an estimated 2 to $4 \%$ of deaths of patients with Type I diabetes have been attributed to hypoglycaemia [4].

Physiological defence against hypoglycaemia. Glucose counterregulation - the physiological mechanisms that normally prevent or rapidly correct hypoglycaemia so effectively that hypoglycaemia is a distinctly uncommon clinical event in people who do not have diabetes - has been reviewed in detail $[4,12]$.

Decreasing plasma glucose concentrations normally trigger a sequence of responses $[13,14,15]$ : (i) decrements in insulin as glucose concentrations decline within the physiological range; (ii) increments in glucagon and epinephrine, among other neuroendocrine responses, as glucose concentrations decrease just below the physiological range and (iii) neurogenic (autonomic) and neuroglycopaenic symptoms, and cognitive impairments, at lower glucose concentrations. Whereas the glycaemic thresholds for these responses (mean arterialised venous plasma glucose concentrations of about $4.5 \mathrm{mmol} / \mathrm{l}(81 \mathrm{mg} / \mathrm{dl}), 3.7 \mathrm{mmol} / \mathrm{l}$ $(67 \mathrm{mg} / \mathrm{dl})$ and $3.0 \mathrm{mmol} / \mathrm{l}(54 \mathrm{mg} / \mathrm{dl})$ respectively) are reproducible in healthy subjects $[13,14,15]$, they shift to higher plasma glucose concentrations in poorly controlled diabetes [16, 17] and to lower plasma glucose concentrations following episodes of hypoglycaemia [18, 19, 20, 21]. These threshold shifts are of considerable relevance to the pathogenesis of iatrogenic hypoglycaemia in diabetes.

Decrements in insulin - which favour increased hepatic (and renal) glucose production and decreased glucose utilisation by insulin-sensitive tissues such as 
Nominal glucose $(\mathrm{mmol} / \mathrm{l})$
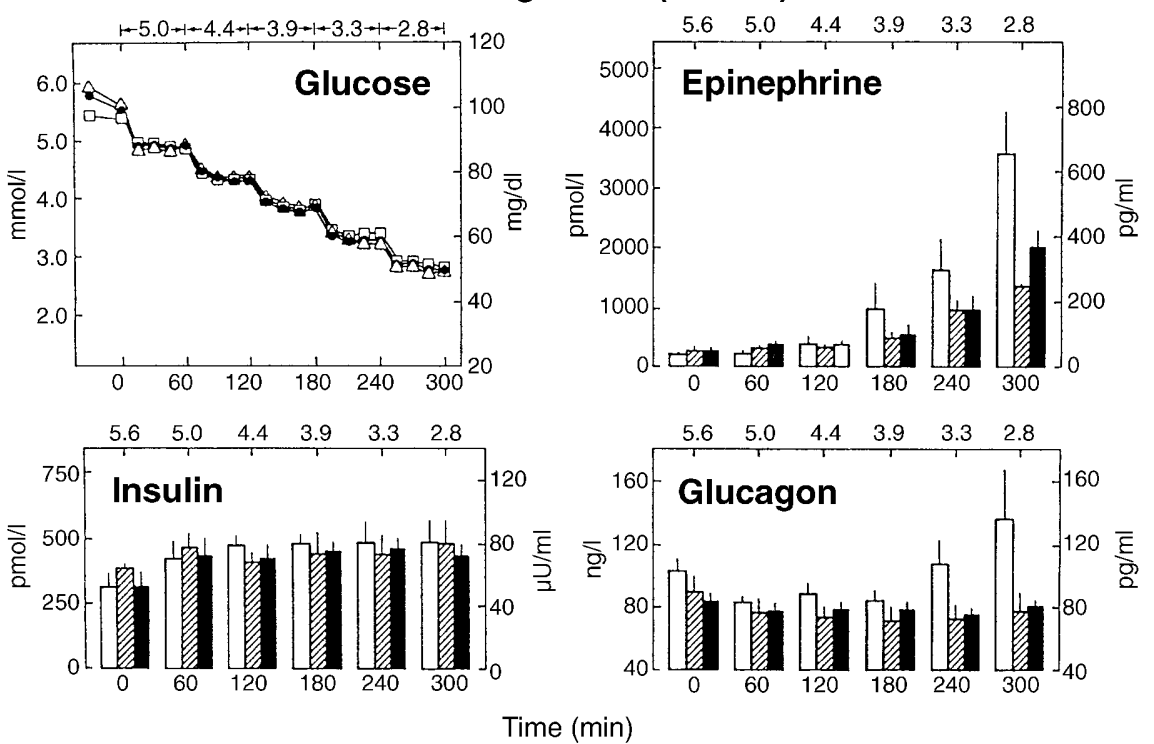

Fig. 1. Mean $( \pm$ SE) arterialized venous plasma glucose, insulin, epinephrine and glucagon concentrations during hyperinsulinaemic stepped hypoglycaemic clamps in non-diabetic subjects (open squares and columns), patients with Type I diabetes with clinical diabetic autonomic neuropathy (CDAN) (open triangles and cross-hatched columns) and patients with Type I diabetes without CDAN (closed squares and columns). Reproduced from reference [21] with permission of the Journal of Clinical Investigation

muscle - are the first defence against falling plasma glucose concentrations [12]. Among the glucose counterregulatory factors, increments in glucagon, which stimulate hepatic glycogenolysis and favour hepatic gluconeogenesis, play a primary role [12]. Although demonstrably involved, increments in epinephrine, which stimulate hepatic (and renal) glucose production and limit glucose utilisation by insulin-sensitive tissues, are not normally critical but become critical when glucagon is deficient [12]. Increments in cortisol and growth hormone, both of which limit glucose utilisation by insulin sensitive tissues and support glucose production, are involved in the defence against prolonged hypoglycaemia but are not critical to recovery from even prolonged hypoglycaemia or to the prevention of hypoglycaemia after an overnight fast [12]. If they are involved, glucose autoregulatory and neural counterregulatory mechanisms play minor roles. Thus, insulin, glucagon and epinephrine stand high in the hierarchy of redundant glucose counterregulatory factors. The secretion of all three hormones is typically impaired in Type I diabetes.

Clinical syndromes of compromised glucose counterregulation. The pathophysiology of glucose counterregulation in diabetes has also been reviewed in detail $[4,5]$.
Absolute or relative therapeutic insulin excess causes plasma glucose concentrations to decline in Type I diabetes. As glucose concentrations decrease insulin concentrations do not decrease; they are unregulated and the result of passive absorption of administered insulin. Furthermore, glucagon concentrations do not increase (Fig. 1) [22]. The latter is a signalling defect. The glucagon responses to other stimuli are largely, if not entirely, intact. The mechanism of the loss of the glucagon in response in Type I diabetes is not known but it is tightly linked to [23], and possibly the result of, endogenous insulin deficiency. Thus, the first and second defences against developing hypoglycaemia are lost in established Type I diabetes. Furthermore, the epinephrine response to falling glucose concentrations, the third defence, is typically attenuated (Fig. 1) [17, 21, 24]. The glycaemic threshold for the epinephrine response is shifted to lower plasma glucose concentrations $[17,21]$, largely the result of recent antecedent hypoglycaemia [21]. The combination of absent glucagon and attenuated epinephrine responses causes the clinical syndrome of defective glucose counterregulation. Patients with combined deficiencies of their glucagon and epinephrine responses have been shown in prospective studies to be at 25 -fold, or at an even higher risk for severe iatrogenic hypoglycaemia during aggressive glycaemic therapy than those with absent glucagon but normal epinephrine responses $[25,26]$. The attenuated epinephrine response is also a marker of an attenuated autonomic, sympathetic neural as well as adrenomedullary, response which causes the clinical syndrome of hypoglycaemia unawareness - loss of the warning, largely neurogenic, symptoms of developing hypoglycaemia. As it compromises behavioural defences against developing hypoglycaemia (eg. the ingestion of food), hypoglycaemia unawareness is also associated with a high frequency of severe iatrogenic hypoglycaemia [27]. 
Hypoglycaemia-associated autonomic failure

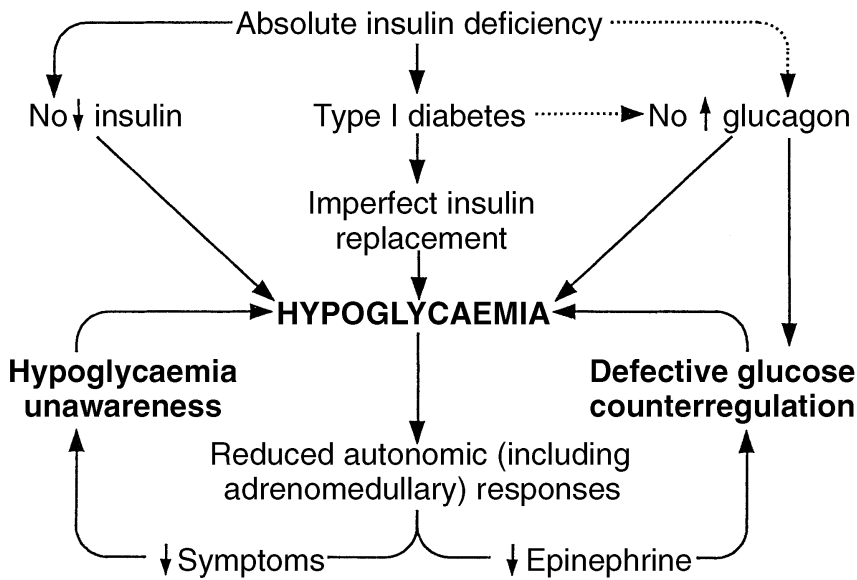

Fig. 2. Schematic diagram of the concept of hypoglycaemiaassociated autonomic failure in Type I diabetes. Modified from reference [28] with permission of the American Diabetes Association

Fig. 3. Mean $( \pm S E)$ arterialised venous plasma glucose and epinephrine concentrations and total symptom scores during hyperinsulinaemic hypoglycaemic clamps on two consecutive mornings with interval afternoon clamped euglycaemia on one occasion (left) and interval afternoon clamped hypoglycaemia on another occasion (right) in healthy subjects. Reproduced from reference [18] with permission of the American Diabetes Association
Hypoglycaemia-associated autonomic failure. The concept of hypoglycaemia-associated autonomic failure (HAAF) [5, 21, 28] in Type I diabetes (Fig. 2) posits that recent antecedent iatrogenic hypoglycaemia causes both defective glucose counterregulation (by reducing the epinephrine response to hypoglycaemia in the setting of an absent glucagon response) and hypoglycaemia unawareness (by reducing the autonomic - sympathetic neural and adrenomedullary response and thus the neurogenic symptom response to hypoglycaemia). The initial hypothesis [28] was based on the original finding that hypoglycaemia today reduces autonomic (including adrenomedullary) and symptomatic responses, among other responses, to subsequent comparable hypoglycaemia in non-diabetic subjects [18, 19] (Fig. 3, 4). There is now considerable support for HAAF in Type I diabetes. Recent antecedent hypoglycaemia has been shown to shift glycaemic thresholds for autonomic (including epinephrine), symptomatic and cognitive dysfunction responses to subsequent hypoglycaemia to lower plasma glucose concentrations [21, 29] (Fig. 5, 6), to impair glycaemic defence against hyperinsulinaemia [21] and to reduce detection of hypoglycaemia in the clinical setting [30] in patients with Type I diabetes. Major support for the concept of HAAF is provided by the finding, from three independent laboratories $[31,32,33]$, that as little as 2 to 3 weeks of scrupulous avoidance of iatrogenic hypoglycaemia reverses hypoglycaemia unawareness (Fig. 7) and improves the epinephrine component of defective glucose counterregulation (Fig. 8) in most affected patients.

\section{Interval (1400-1600 h) \\ Euglycemia \\ Hypoglycaemia}
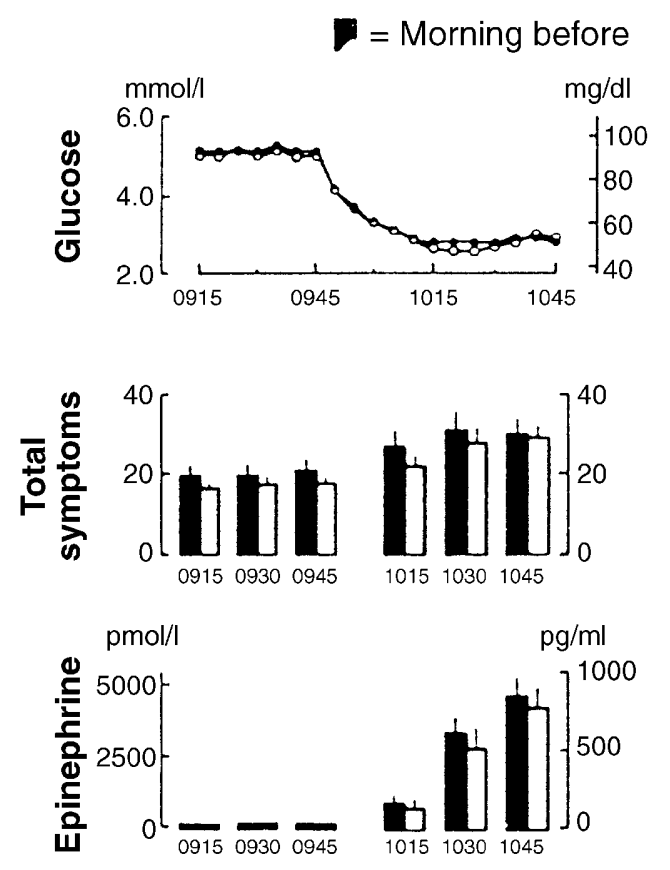
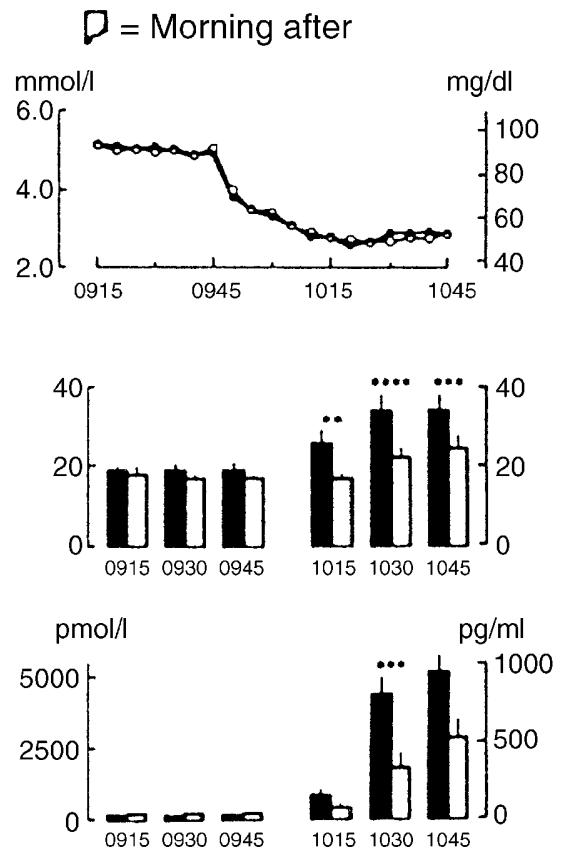

Clock time (hours) 


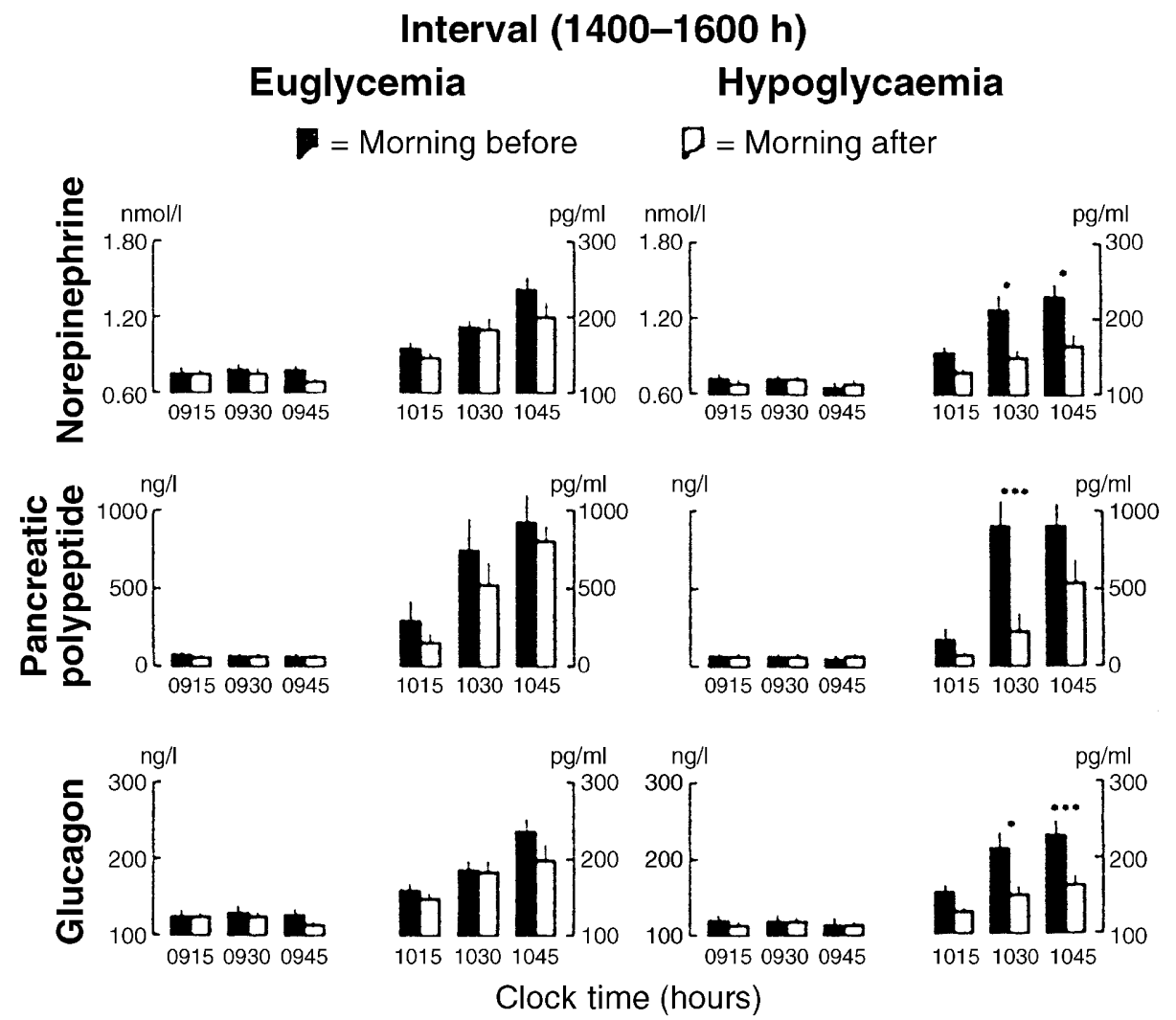

Fig. 4. Mean $( \pm \mathrm{SE})$ arterialised venous plasma norepinephrine, pancreatic polypeptide and glucagon concentrations during hyperinsulinaemic hypoglycaemic clamps on two consecutive mornin gs with interval afternoon clamped euglycaemia on one

occasion (left) and interval afternoon clamped hypoglycaemia on another occasion (right) in healthy subjects. Reproduced from reference [18] with permission of the American Diabetes Association

Nominal glucose $(\mathrm{mmol} / \mathrm{l})$
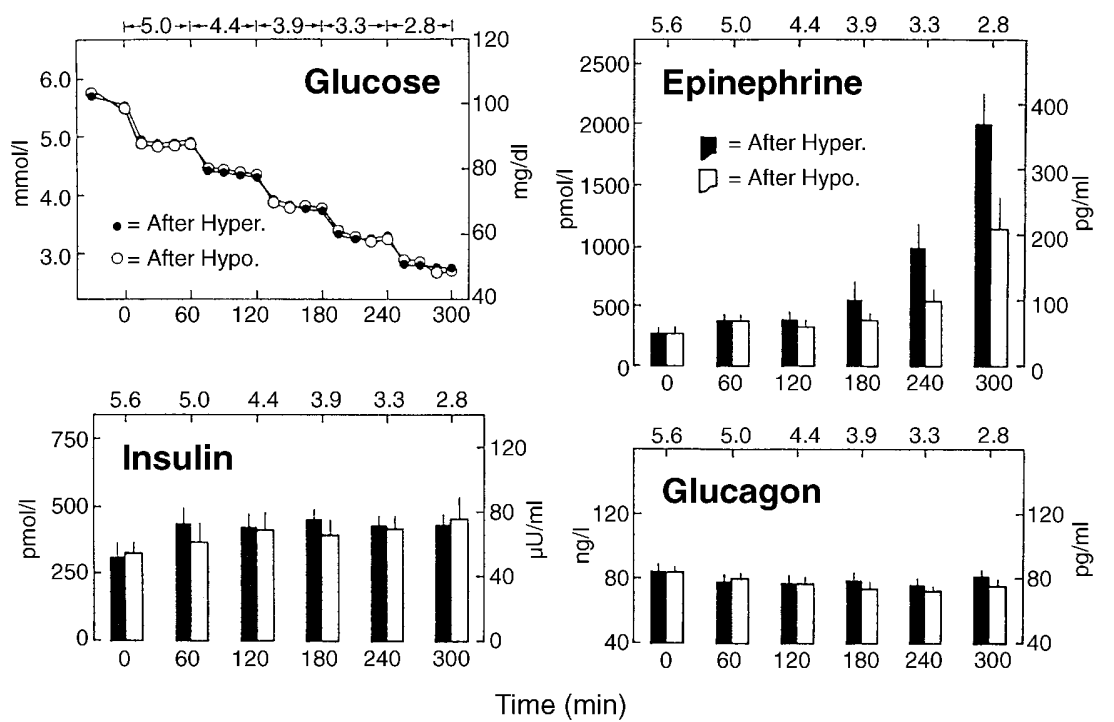

Fig. 5. Mean ( \pm SE) arterialised venous plasma glucose, insulin, epinephrine and glucagon concentrations during hyperinsulinaemic stepped hypoglycaemic clamps in patients with Type I diabetes studied the morning after clamped hyperglycemia the previous day on one occasion $(\boldsymbol{\square}, \mathbf{0})$ and after clamped hypoglycaemia the previous day on another occasion $(\square, \bigcirc)$. Reproduced from reference [21] with permission of the Journal of Clinical Investigation

Notably, the absent glucagon response is not restored [31, 32, 33] (Fig. 8).

Studies of the mediator and mechanism of HAAF are ongoing in our laboratory and elsewhere [5]. It has been suggested that the cortisol response to antecedent hypoglycaemia mediates HAAF $[34,35,36]$. They found that antecedent cortisol infusion [34], and antecedent exercise (which releases cortisol) [35], mimics 


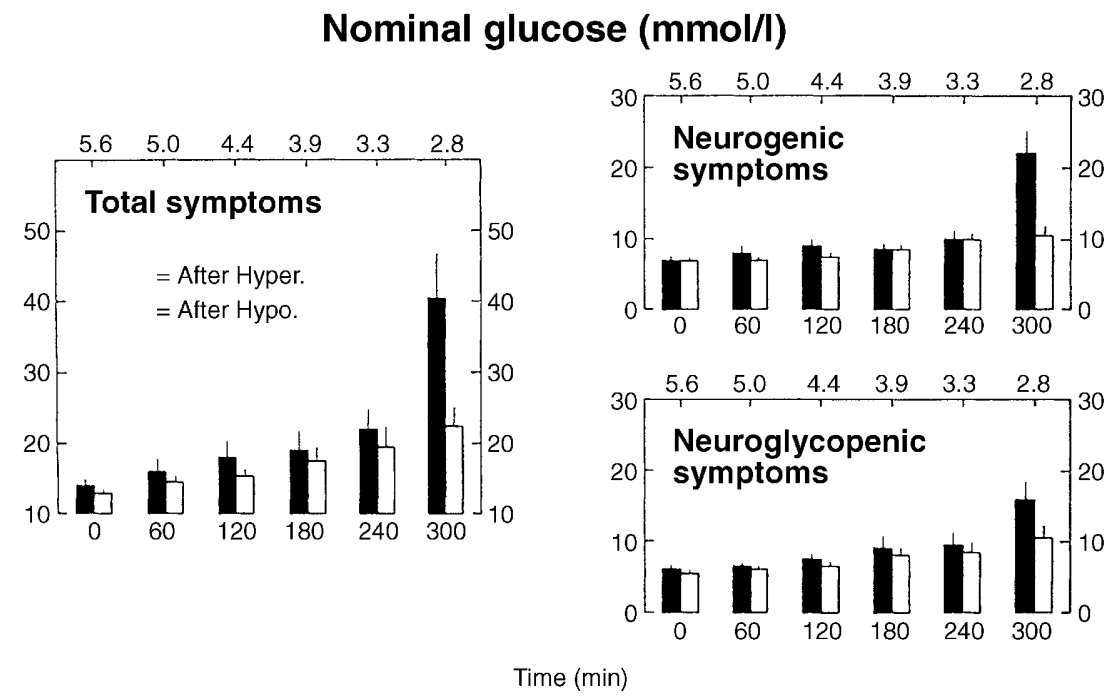

Fig. 6. Mean ( \pm SE) total, neurogenic (autonomic) and neuroglycopenic symptoms scores during hyperinsulinaemic stepped hypoglycaemic clamps in patients with Type I diabetes studied the morning after clamped hyperglycaemia the previous day on

one occasion ( $\boldsymbol{\square})$ and after clamped hypoglycaemia the previous day on another occasion $(\square)$. Reproduced from reference [21] with permission of the Journal of Clinical Investigation

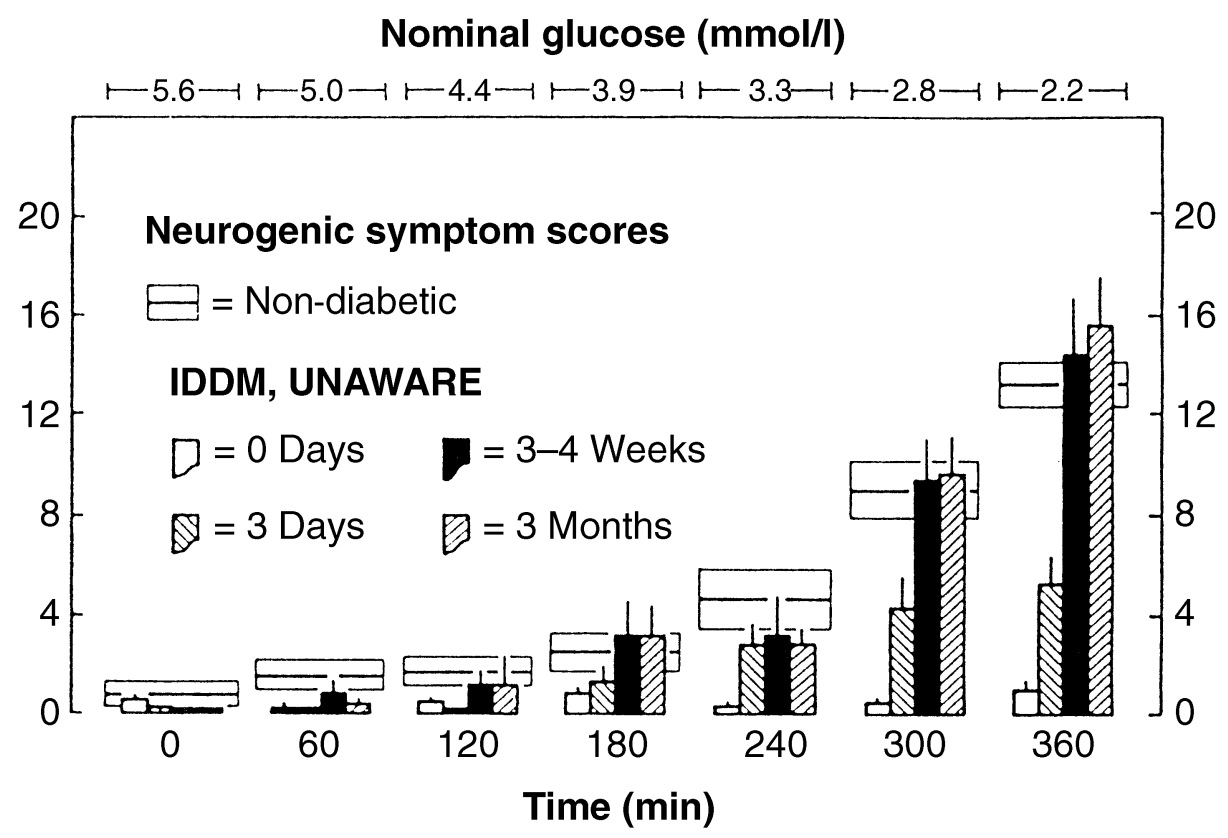

Fig. 7. Mean $( \pm \mathrm{SE})$ neurogenic (autonomic) symptom scores during hyperinsulinaemic stepped hypoglycaemic clamps in non-diabetic subjects (rectangles) and in patients with Type I diabetes selected for clinical hypoglycaemia unawareness and studied at baseline ( 0 days, open columns), after 3 days of strict avoidance of hypoglycaemia as General Clinical Research Center inpatients ( 3 days, first set of cross-hatched columns), after 3-4 weeks of scrupulous outpatient avoidance of hypoglycaemia (3-4 weeks, closed columns) and after 3 months of scrupulous outpatient avoidance of hypoglycaemia ( 3 months, second set of cross-hatched columns). Reproduced from reference [33] with permission of the American Diabetes Association the phenomenon and that deficient cortisol secretion minimises the effects of antecedent hypoglycaemia [36]. We found antecedent exercise to have a more limited impact [37]. Among the responses to subsequent hypoglycaemia, only the epinephrine response was reduced, and that by only about $30 \%$, after exercise. Furthermore, the symptom responses to hypoglycaemia were not reduced in either study [35, 37]. Thus, an additional factor, or factors, are likely to be involved in the mediation of HAAF.

Concerning the mechanism of HAAF, the brain glucose transport hypothesis is based on the finding that days to weeks of hypoglycaemia increase brain glucose uptake as well as brain microvascular (i.e., blood-brain barrier) GLUT-1 mRNA and protein in 
Nominal glucose ( $\mathrm{mmol} / \mathrm{l})$
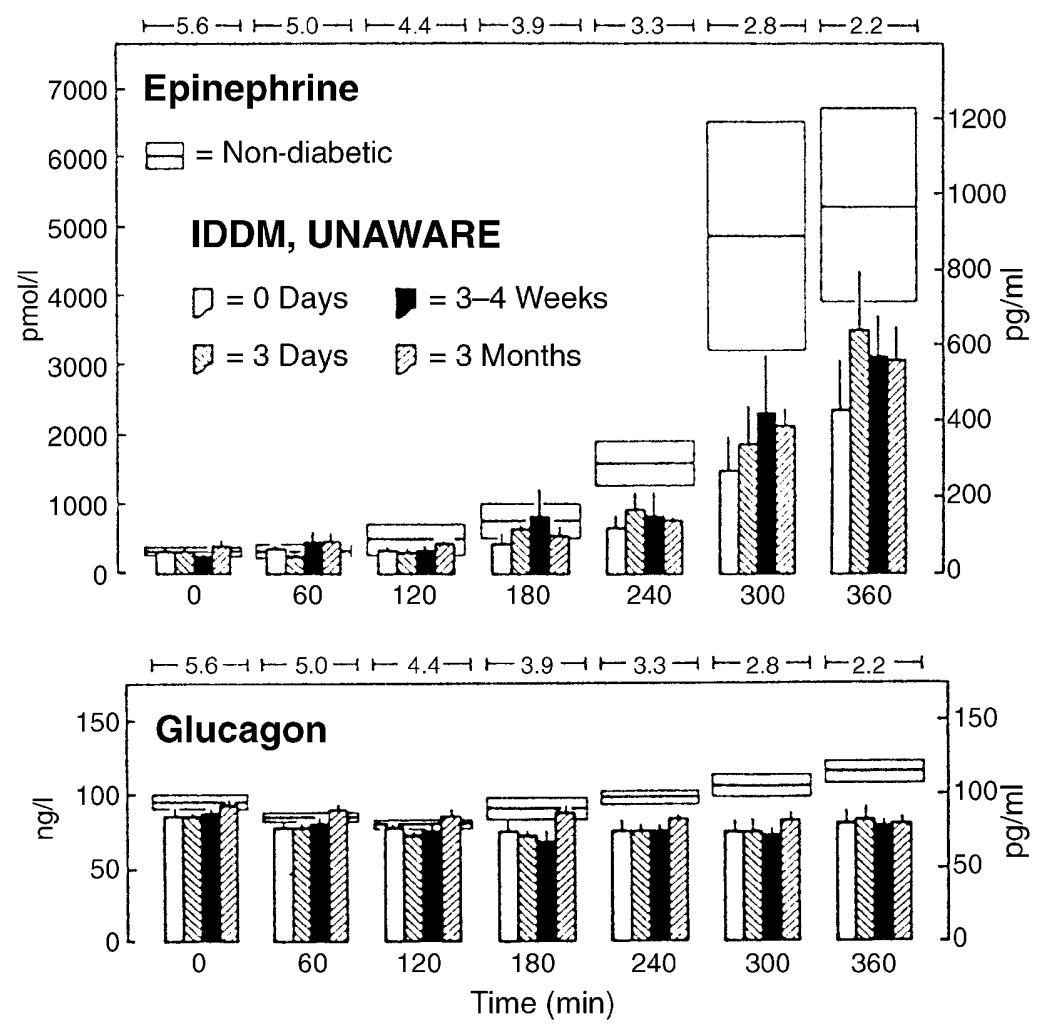

Fig. 8. Mean $( \pm S E)$ arterialised venous plasma epinephrine and glucagon concentrations during hyperinsulinaemic stepped hypoglycaemic clamps in non-diabetic subjects (rectangles) and in patients with Type I diabetes selected for clinical hypoglycaemia unawareness and studied at baseline ( 0 days, open columns), after 3 days of strict avoidance of hypoglycaemia as General Clinical Research Center inpatients (3 days, first set of cross-hatched columns), after 3-4 weeks of scrupulous outpatient avoidance of hypoglycaemia (3-4 weeks, closed columns) and after 3 months of scrupulous outpatient avoidance of hypoglycaemia (3 months, second set of cross-hatched columns). Reproduced from reference [33] with permission of the American Diabetes Association

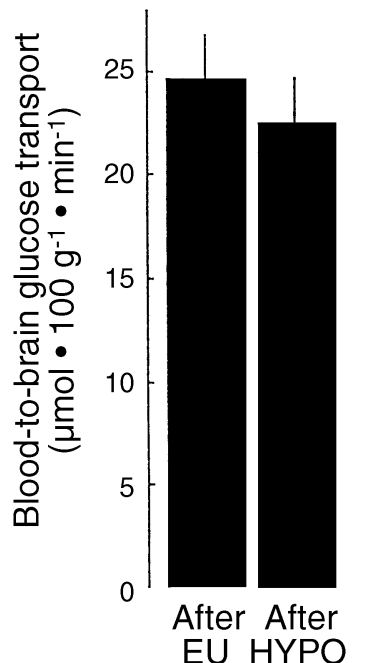

Fig. 9. Mean $( \pm \mathrm{SE})$ blood-to-brain glucose transport and cerebral glucose metabolism, measured with $\left[1-{ }^{11} \mathrm{C}\right]$ glucose and positron emission tomography (PET), and cerebral blood flow, measured with $\left[{ }^{15} \mathrm{O}\right]$ water and PET, in healthy subjects studied after euglycaemia (After EU) and after approximately $24 \mathrm{~h}$ of interprandial hypoglycaemia ( $3.0 \mathrm{mmol} / \mathrm{l}$ ) (After HYPO). Reproduced from reference [41] with permission of the American Diabetes Association
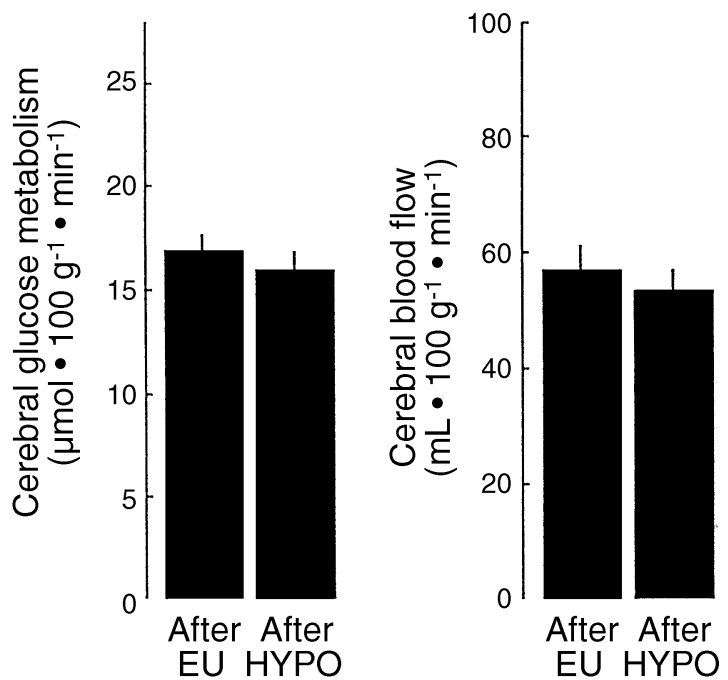

rodents (eg. [38]). Using the Kety-Schmidt technique, it has been reported that $56 \mathrm{~h}$ of interprandial hypoglycaemia increased brain glucose uptake during hypoglycaemia in non-diabetic subjects [39] and that brain glucose uptake during hypoglycaemia was preserved in patients with well controlled (ie. frequently hypoglycaemic) Type I diabetes [40]. However, we 
found that global blood-to-brain glucose transport and cerebral glucose metabolism, measured with [1${ }^{11} \mathrm{Clglucose}$ and positron emission tomography (PET), and cerebral blood flow, measured with $\left[{ }^{15} \mathrm{O}\right]$ water and PET, were not increased after approximately $24 \mathrm{~h}$ of interprandial hypoglycaemia in healthy subjects [41] (Fig. 9). The latter data do not support the hypothesis that increased blood-to-brain glucose transport is the mechanism of HAAF. They do not exclude increased regional glucose transport. Alternatively, the alteration could lie beyond the blood-brain barrier.

Finally, we and others have begun to study the mechanisms of the normal glucagon response to hypoglycaemia with the aim of gaining insight into the mechanism of the absence of the glucagon response in Type I diabetes [22], a critical component of defective glucose counterregulation and HAAF. We have focused on the intraislet insulin hypothesis: a decrease in beta-cell insulin secretion, and thus a decrease in tonic intraislet $\alpha$-cell inhibition by insulin, is normally a signal for increased glucagon secretion in response to hypoglycaemia. Prevention of the normal decrease in intraislet insulin, by infusion of the beta-cell secretagogue tolbutamide, selectively prevented the glucagon response to hypoglycaemia despite an entirely normal autonomic response in healthy subjects [42]. Taken together, the available data suggest a fundamental interaction between decrements in $\alpha$-cell glucose and intraislet insulin in the normal glucagon response to hypoglycaemia. If so, loss of the signal of a decrease in intraislet insulin would plausibly explain loss of the glucagon response to hypoglycaemia in Type I diabetes.

\section{Pathophysiology of Glucose Counterregulation in Type II diabetes mellitus}

Relative frequency of hypoglycaemia. In general, the frequency of iatrogenic hypoglycaemia is substantially lower in Type II diabetes than in Type I diabetes. Representative event rates for severe hypoglycaemia (requiring the assistance of another person) in Type I diabetes are from 62 to 170 episodes per 100 patient years $[1,10,11]$. Those reported during aggressive insulin therapy of Type II diabetes range from 3 to 73 episodes per 100 patient years [10, 43, 44]. Thus, the rates of severe hypoglycaemia are roughly tenfold lower in Type II diabetes even during aggressive therapy with insulin. The rates are even lower in patients with Type II diabetes treated with oral hypoglycaemic agents. However, quantitative data from patients with Type II diabetes treated to near euglycaemia are limited. Over 6 years of follow-up of patients with Type II diabetes in the UKPDS, $2.4 \%$ of those using metformin, $3.3 \%$ of those using a sulfonylurea and $11.2 \%$ of those using insulin, reported major hypoglycaemia (requiring medical attention or admission to hospital)
[45]. For comparison, 65\% of the intensively treated patients with Type I diabetes in the DCCT suffered severe hypoglycaemia (requiring the assistance of another individual) over 6.5 years of follow-up [1]. Since the UKPDS involved newly diagnosed Type II diabetes and the patients' glycaemic control was not as strict as in the DCCT, the UKPDS data could well underestimate the frequency of iatrogenic hypoglycaemia in Type II diabetes.

Clinical experience suggests that iatrogenic hypoglycaemia becomes an increasingly frequent problem over time in Type II diabetes. Indeed, hypoglycaemia was found to become progressively more limiting to glycaemic control over time in the UKPDS [45, 46]. The UKPDS investigators noted that "...patients often did not achieve normoglycaemia. This was in part because of the high incidence of insulin-induced hypoglycaemia, which is a limitation in treating patients with Type II diabetes just as it is in patients with Type I diabetes" [46]. Furthermore, in one series the frequencies of severe hypoglycaemia were similar in Type II diabetes and Type I diabetes matched for duration of insulin therapy [47]. Given progressive insulin deficiency in Type II diabetes [45], these findings indicate that iatrogenic hypoglycaemia becomes a progressively more frequent clinical problem for patients with Type II diabetes as they approach the insulin deficient end of the spectrum of Type II diabetes.

Compromised glucose counterregulation. The relatively low overall frequencies of iatrogenic hypoglycaemia suggest that glucose counterregulatory mechanisms are largely intact early in the course of Type II diabetes. As discussed above, regulated insulin and glucagon secretion, and without the latter epinephrine secretion, normally play key roles in the prevention of hypoglycaemia [12]. Glucagon responses to hypoglycaemia have been reported to be normal $[48,49,50]$ or reduced but not absent $[51,52,53]$ in studies of unselected patients with Type II diabetes. Epinephrine responses have not been found to be reduced.

We tested the hypothesis that the glucagon response to hypoglycaemia is reduced in patients approaching the insulin deficient end of the spectrum of Type II diabetes [54]. Patients with Type II diabetes were selected for a longstanding requirement for therapy with insulin, a clinical surrogate for endogenous insulin deficiency. The latter was confirmed by documentation of low plasma C-peptide concentrations; indeed, the C-peptide concentrations were in the range often found in Type I diabetes [55] (but the absence of antibodies to glutamic acid decarboxylase, an inclusion criterion, provided evidence against late onset of Type I diabetes). In these patients with insulin deficient Type II diabetes the glucagon response to hypoglycaemia was virtually absent [54]. Thus, glucagon responses to hypoglycaemia are reduced in advanced Type II diabetes, those patients approaching 
Table 1. Pathophysiology of glucose counterregulation in Type I and Type II diabetes. Iatrogenic hypoglycaemia is the result of the interplay of absolute or relative insulin excess and com- promised glucose counterregulation in Type I diabetes and in advanced Type II diabetes mellitus.

\begin{tabular}{lccc}
\hline Glucose & Insulin & Glucagon & Epinephrine \\
\hline$\downarrow$ Non-diabetic & $\downarrow$ & $\uparrow$ & $\uparrow$ \\
$\downarrow$ Type I diabetes mellitus & No $\downarrow$ & No $\uparrow$ & Attenuated $\uparrow$ \\
\hline
\end{tabular}

Defective glucose counterregulation (absent glucagon and attenuated epinephrine responses)

Hypoglycaemia unawareness (attenuated autonomic, including adrenomedullary and sympathetic neural, responses and the resulting neurogenic symptoms)

\begin{tabular}{llll}
\hline$\downarrow$ Type II diabetes mellitus & $\downarrow$ & $\uparrow$ & $\uparrow$ \\
$\downarrow$ Advanced Type II diabetes mellitus & $\stackrel{\downarrow}{\text { No } \downarrow}$ & No $\uparrow$ & Attenuated $\uparrow$ \\
\hline
\end{tabular}

the insulin-deficient end of the spectrum of Type II diabetes, as they are in Type I diabetes. These patients, and an additional group of less well controlled patients with Type II diabetes treated with oral agents, were restudied after two episodes of induced hypoglycaemia the previous day. This recent antecedent hypoglycaemia was shown to shift the glycaemic thresholds for autonomic (including epinephrine) and symptomatic responses, among other responses, to subsequent hypoglycaemia to lower plasma glucose concentrations in Type II diabetes, as it does in Type I diabetes. Thus, patients with advanced Type II diabetes are at risk for developing defective glucose counterregulation and hypoglycaemia unawareness, the components of hypoglycaemia-associated autonomic failure, analogous to that which occurs in Type I diabetes. This could explain why iatrogenic hypoglycaemia limits glycaemic control as patients approach the insulin deficient end of the spectrum of Type II diabetes $[45,46,47]$.

The pathophysiology of glucose counterregulation in Type II and Type I diabetes is summarised (Table 1). Whereas glucose counterregulation is compromised early in the course of Type I diabetes, defences against decreasing plasma glucose concentrations decrements in insulin and increments in glucagon and epinephrine - appear to be preserved early in the course of Type II diabetes. However, these are compromised over time as the patient approaches the insulin deficient end of the spectrum of Type II diabetes. Thus, over time the risk of hypoglycaemia in Type II diabetes approaches that in Type I diabetes $[45,46,47]$.

\section{Clinical Risk Factors and Risk Factor Reduction}

The conventional risk factors and the more recently recognized risk factors for iatrogenic hypoglycaemia and an approach to clinical hypoglycaemia risk factor reduction have been reviewed $[4,56]$.
Conventional risk factors: insulin excess. The conventional risk factors for iatrogenic hypoglycaemia [56], conceptualised in Type I diabetes but relevant to Type II diabetes, are based on the premise that absolute or relative insulin excess, whether injected or secreted insulin, is the sole determinant of risk. Absolute or relative insulin excess occurs when: (i) insulin, or insulin secretagogue or sensitizer, doses are excessive, ill-timed or of the wrong type; (ii) exogenous glucose delivery is decreased after missed meals or snacks and during the overnight fast; (iii) endogenous glucose production is decreased after alcohol ingestion; (iv) glucose utilisation is increased during exercise; (v) sensitivity to insulin is increased late after exercise, in the middle of the night and after weight loss, increased fitness or improved glycaemic control or during treatment with an insulin sensitizer; (vi) insulin clearance is decreased as in renal failure. Although they must be considered carefully, these conventional risk factors explain only a minority of episodes of severe iatrogenic hypoglycaemia, at least in Type I diabetes [57]. Patients with diabetes occasionally suffer from other hypoglycaemic disorders that occur in people without diabetes [4], and these increase the risk of iatrogenic hypoglycaemia. They are a rare, but sometimes treatable, cause of hypoglycaemia in diabetes.

Insulin excess plus compromised glucose counterregulation. Although hypoglycaemia can, of course, result from insulin excess alone, iatrogenic hypoglycaemia is more appropriately viewed as the result of the interplay of insulin excess and compromised glucose counterregulation in Type I diabetes and advanced Type II diabetes (Table 1) [4, 56]. Risk factors related to compromised glucose counterregulation that are well established in Type I diabetes [1, 23, 58] and are likely to be relevant in advanced Type II diabetes, include: (i) insulin deficiency; (ii) a history of severe hypoglycaemia, hypoglycaemia unawareness, or both; (iii) aggressive glycaemic therapy per se as evidenced by 
lower haemoglobin $\mathrm{A}_{1 \mathrm{C}}$ concentrations, lower glycaemic goals, or both. These are clinical surrogates of compromised glucose counterregulation. Insulin deficiency indicates that insulin concentrations will not decrease and predicts accurately that glucagon concentrations will not increase [23] as glucose concentrations decrease. A history of severe hypoglycaemia indicates, and that of hypoglycaemia unawareness or even aggressive therapy per se implies, recent antecedent hypoglycaemia. The latter is the proximate cause of hypoglycaemia-associated autonomic failure. Obviously, because of the pharmacokinetic imperfections of all glucose-lowering therapies, iatrogenic hypoglycaemia occurs in the absence of these risk factors [56]. Nevertheless, the risk is increased considerably in their presence $[1,23,58]$.

Risk factor reduction. Reducing the risk of iatrogenic hypoglycaemia, while attempting to hold plasma glucose concentrations as close to the non-diabetic range as can be accomplished safely, involves three steps [56]: (i) Addressing the issue of hypoglycaemia during every visit with the patient; (ii) applying the principles of aggressive therapy - patient education and empowerment, frequent self-monitoring of blood glucose, flexible insulin or other drug regimens, individualised glycaemic goals and ongoing professional guidance and support; (iii) considering both the conventional risk factors and those indicative of compromised glucose counterregulation. With respect to the latter, clinical hypoglycaemia unawareness (which also implies defective glucose counterregulation) is a clear clue to recurrent antecedent hypoglycaemia. Given a history of hypoglycaemia unawareness a 2 to 3 week period of scrupulous avoidance of hypoglycaemia, which can be assessed by the return of awareness, is advisable [31, 32, 33].

\section{Perspective}

Although it is possible to minimize the risk of hypoglycaemia while attempting to achieve and maintain some degree of glycaemic control [56], iatrogenic hypoglycaemia remains the limiting factor in the glycaemic management of diabetes. It is not practical to eliminate hypoglycaemia from the lives of patients with Type I diabetes, and many with Type II diabetes mellitus, with available treatment regimens without compromising glycaemic control. Due to the barrier of hypoglycaemia the vast majority of people with diabetes do not have normal haemoglobin $\mathrm{A}_{1 \mathrm{C}}$ concentrations and are at risk for the macrovascular and the microvascular complications of the disease. Pending the prevention and cure of diabetes, true euglycaemia will require treatment methods that provide plasma glucose-regulated insulin replacement or secretion. In the meantime we need to learn to replace insulin in a much more physiological fashion, to prevent, correct or compensate for compromised glucose counterregulation, or both if we are to achieve near euglycaemia safely and thus more fully realise the benefits of glycaemic control in people with diabetes.

Sources. This 2001 Claude Bernard Lecture of the European Association for the Study of Diabetes is based on studies of the physiology of glucose counterregulation, its pathophysiology in people with diabetes and the relationship of the latter to clinical hypoglycaemia by many investigators including the author and his collaborators and colleagues over the past three decades. The body of knowledge, of course, stems from the seminal discoveries of Claude Bernard (1813-1878) and the approach from his view of integrated physiology: "...if we break up a living organism by isolating its different parts it is only for the sake of ease in experimental analysis ... Indeed when we wish to ascribe to a physiological quality its value and true significance we must always ... draw our final conclusion only in relation to its effects in the whole." [59].

Acknowledgements. The author's work cited in this review was supported in part by U.S.P.H.S. grants R37 DK27085, M01 RR00036, P60 DK20579 and T32 DK07120 and a fellowship award from the American Diabetes Association. The author gratefully acknowledges the substantive contributions of his mentors, collaborators and postdoctoral fellows to the work described in this review. The skilled assistance of the research nursing, dietary, laboratory, informatics and biostatistical staffs of the Washington University General Clinical Research Center is also appreciated. Ms. K. Muehlhauser provided invaluable support and prepared the manuscript.

\section{References}

1. The Diabetes Control and Complications Trial Research Group (1993) The effect of intensive treatment of diabetes on the development and progression of long-term complications in insulin-dependent diabetes mellitus. N Engl J Med 329:977-986

2. The United Kingdom Prospective Diabetes Study Research Group (1998) Intensive blood-glucose control with sulfonylureas or insulin compared with conventional treatment and risk of complications in patients with type 2 diabetes. Lancet 352:837-853

3. Cryer PE (1994) Hypoglycemia: The limiting factor in the management of IDDM. Diabetes 43:1378-1389

4. Cryer PE (1997) Hypoglycemia. Pathophysiology, Diagnosis and Treatment. Oxford University Press: New York

5. Cryer PE (2001) Hypoglycemia-associated autonomic failure in diabetes. Am J Physiol 281:E1115-E1121

6. Stratton IM, Adler AI, Neil HAW et al. (2000) Association of glycaemia with macrovascular and microvascular complications of type 2 diabetes (UKPDS 35): prospective observational study. BMJ 321:405-412

7. Khaw K-T, Wareham N, Luben R et al. (2001) Glycated haemoglobin, diabetes, and mortality in men in Norfolk cohort of European Prospective Investigation of Cancer and Nutrition (EPIC-Norfolk). BMJ 322:1-6 
8. Boland E. Monsod T, Delucia M, Brandt CA, Fernando S, Tamborlane WV (2001) Limitations of conventional methods of self-monitoring of blood glucose. Diabetes Care 24: 1858-1862

9. Gross, TM, Mastrototaro JJ, Fredrickson LP (2001) Detection of unseen hypoglycemia using continuous glucose monitoring. Diabetologia 43:A5 (Abstract)

10. MacLeod KM, Hepburn DA, Frier BM (1993) Frequency and morbidity of severe hypoglycemia in insulin-treated diabetic patients. Diabet Med 10:238-245

11. Reichard P, Berglund B, Britz A, Cars I, Nilsson BY, Rosenqvist U (1991) Intensified conventional insulin treatment retards the microvascular complications of insulin-dependent diabetes mellitus (IDDM): The Stockholm Diabetes Intervention Study (SDIS) after 5 years. J Intern Med 230:101-108

12. Cryer PE (2001) The prevention and correction of hypoglycemia. Handbook of Physiology. In: Jefferson LS, Cherrington $\mathrm{AD}$ (eds) Section 7, The Endocrine System. The Endocrine Pancreas and Regulation of Metabolism Vol II, Oxford University Press, New York pp 1057-1092

13. Schwartz NS, Clutter WE, Shah SD, Cryer PE (1987) Glycemic thresholds for activation of glucose counterregulatory systems are higher than the threshold for symptoms. J Clin Invest 79:777-781

14. Mitrakou A, Ryan C, Veneman T et al. (1991) Hierarchy of glycemic thresholds for counterregulatory hormone secretion, symptoms and cerebral dysfunction. Am J Physiol 260:E67-E74

15. Fanelli C, Pampanelli S, Epifano L et al. (1994) Relative roles of insulin and hypoglycemia on induction of neuroendocrine responses to, symptoms of, and deterioration of cognitive function in hypoglycemia in male and female humans. Diabetologia 37:797-807

16. Boyle PJ, Schwartz NS, Shah SD, Clutter WE, Cryer PE (1988) Plasma glucose concentrations at the onset of hypoglycemic symptoms in patients with poorly controlled diabetes and nondiabetics. N Engl J Med 318:1487-1492

17. Amiel SA, Sherwin RS, Simonson DC, Tamborlane WV (1988) Effect of intensive insulin therapy on glycemic thresholds for counterregulatory hormone release. Diabetes 37:901-907

18. Heller SR, Cryer PE (1991) Reduced neuroendocrine and symptomatic responses to subsequent hypoglycemia after one episode of hypoglycemia in nondiabetic humans. Diabetes 40:223-226

19. Davis MR, Shamoon H (1991) Counterregulatory adaptation to recurrent hypoglycemia in normal humans. J Clin Endocrinol Metab 73:995-1001

20. Mitrakou A, Fanelli C, Veneman T et al. (1993) Reversibility of hypoglycemia unawareness in patients with an insulinoma. N Engl J Med 329:834-839

21. Dagogo-Jack SE, Craft S, Cryer PE (1993) Hypoglycemiaassociated autonomic failure in insulin dependent diabetes mellitus. J Clin Invest 91:819-828

22. Gerich JE, Langlois M, Noacco C, Karam JH, Forsham PH (1973) Lack of glucagon response to hypoglycemia in diabetes: Evidence for an intrinsic pancreatic alpha cell defect. Science 182:171-173

23. Fukuda M. Tanaka A, Tahara Y et al. (1988) Correlation between minimal secretory capacity of pancreatic $\beta$-cells and stability of diabetic control. Diabetes 37:81-88

24. Bolli G, De Feo P, Compagnucci P et al. (1983) Abnormal glucose counterregulation in insulin-dependent diabetes mellitus: interaction of anti-insulin antibodies and impaired glucagon and epinephrine secretion. Diabetes 32:134 141
25. White NH, Skor D, Cryer PE, Bier DM, Levandoski L, Santiago, JV (1983) Identification of type 1 diabetic patients at increased risk for hypoglycemia during intensive therapy. N Engl J Med 308:485-491

26. Bolli GB, De Feo P, De Cosmo S et al. (1984) A reliable and reproducible test for adequate glucose counterregulation in type 1 diabetes. Diabetes 33:732-737

27. Gold AE, MacLeod KM, Frier BM (1994) Frequency of severe hypoglycemia in patients with type 1 diabetes with impaired awareness of hypoglycemia. Diabetes Care 17:697-703

28. Cryer PE (1992) Iatrogenic hypoglycemia as a cause of hypoglycemia-associated autonomic failure in IDDM: A vicious cycle. Diabetes 41:255-260

29. Fanelli CG, Paramore DS, Hershey T et al. (1998) Impact of nocturnal hypoglycemia on hypoglycemic cognitive dysfunction in type 1 diabetes mellitus. Diabetes 47:19201927

30. Ovalle F, Fanelli CG, Paramore DS, Hershey T, Craft S, Cryer PE (1998) Brief twice weekly episodes of hypoglycemia reduce detection of clinical hypoglycemia in type 1 diabetes mellitus. Diabetes 47:1472-1479

31. Fanelli CG, Pampanelli S, Epifano L et al. (1994) Longterm recovery from unawareness, deficient counterregulation and lack of cognitive dysfunction during hypoglycemia following institution of rational intensive therapy in IDDM. Diabetologia 37:1265-1276

32. Cranston I, Lomas J, Maran A, Macdonald I, Amiel S (1994) Restoration of hypoglycemia unawareness in patients with long duration insulin-dependent diabetes mellitus. Lancet 344:283-287

33. Dagogo-Jack S, Rattarasarn C, Cryer PE (1994) Reversal of hypoglycemia unawareness, but not defective glucose counterregulation, in IDDM. Diabetes 43:1426-1434

34. Davis SN, Shavers C, Costa F, Mosqueda-Garcia R (1996) Role of cortisol in the pathogenesis of deficient counterregulation after antecedent hypoglycemia in normal humans. J Clin Invest 98:680-691

35. Galassetti P, Mann S, Tate D et al. (2001) Effects of antecedent prolonged exercise on subsequent counterregulatory responses to hypoglycemia. Am J Physiol 280:E908-E917

36. Davis SN, Shavers C, Davis B, Costa F (1997) Prevention of an increase in plasma cortisol during hypoglycemia preserves subsequent counterregulatory responses. J Clin Invest 100:429-438

37. McGregor VP, Greiwe JS, Banarer S, Cryer PE (2001) Limited impact of vigorous exercise on defenses against hypoglycemia. Diabetes (in press)

38. Simpson IA, Appel NM, Hokari M et al. (1999) Blood-barrier glucose transporter: Effects of hypo- and hyperglycemia revisited. J Neurochem 72:238-247

39. Boyle PJ, Nagy RJ, O'Connor AM, Kempers SF, Yeo RA, Qualls C (1994) Adaptation in brain glucose uptake following recurrent hypoglycemia. Proc Natl Acad Sci USA 91: 9352-9356

40. Boyle PJ, Kempers SF, O'Connor AM, Nagy RJ (1995) Brain glucose uptake and unawareness of hypoglycemia in patients with insulin dependent diabetes mellitus. N Engl J Med 333:1726-1731

41. Segel SA, Fanelli CG, Dence CS et al. (2001) Blood-tobrain glucose transport, cerebral glucose metabolism and cerebral blood flow are not increased following hypoglycemia. Diabetes 50:1911-1917

42. Banarer S, McGregor VP, Cryer PE (2002) Intraislet hyperinsulinemia prevents the glucagon response to hypoglycemia despite an intact autonomic response. Diabetes 51: 958-965 
43. Abaira C, Colwell JA, Nuttall FQ et al. (1995) Veterans affairs cooperative study on glycemic control and complications in type II diabetes: results of the feasibility trial. Diabetes Care 18:1113-1123

44. Saudek CD, Duckworth WC, Giobbie-Hurder A et al. (1996) Implantable insulin pump vs. multiple-dose insulin for non-insulin dependent diabetes mellitus. A randomized clinical trial. JAMA 276:1249-1258

45. The United Kingdom Prospective Diabetes Study Research Group (1995) UK Prospective Study 16: Overview of 6 years' therapy of type II diabetes: a progressive disease. Diabetes 44:1249-1258

46. The United Kingdom Prospective Diabetes Study Research Group (1998) UK Prospective Study 24: A 6-year, randomized, controlled trial comparing sulfonylurea, insulin and metformin therapy in patients with newly diagnosed type 2 diabetes that could not be controlled with diet therapy. Ann Intern Med 128:165-175

47. Hepburn DA, MacLeod KM, Pell ACH, Scougal IJ, Frier BM (1993) Frequency and symptoms of hypoglycemia experienced by patients with type 2 diabetes treated with insulin. Diabet Med 10:231-237

48. Boden G, Soriano M, Hoeldtke RD, Owen OE (1983) Counterregulatory hormone release and glucose recovery after hypoglycemia in non-insulin-dependent diabetic patients. Diabetes 32:1055-1059

49. Heller SR, Macdonald IA, Tattersall RB (1987) Counterregulation in Type II (non-insulin-dependent) diabetes mellitus. Normal endocrine and glycaemic responses, up to ten years after diagnosis. Diabetologia 30:924-929

50. Peacey SR, Robinson R, Bedford C et al. (2000) Does the choice of treatment for type 2 diabetes affect the physiological response to hypoglycemia? Diabetes Care 23:10221023
51. Bolli G, Tsalikian E, Haymond M, Cryer P, Gerich J (1984) Defective glucose counterregulation after subcutaneous insulin in noninsulin dependent diabetes mellitus: paradoxical suppression of glucose utilization and lack of compensatory increase in glucose production, roles of insulin resistance, abnormal neuroendocrine responses and islet paracine interactions. J Clin Invest 73:1532-1541

52. Meneilly GS, Cheung E, Tuokko H (1994) Counterregulatory hormone responses to hypoglycemia in the elderly patient with diabetes. Diabetes 43:403-410

53. Shamoon H, Friedman S, Canton C, Zacharowicz L, Hu M, Rossetti L (1994) Increased epinephrine and skeletal muscle responses to hypoglycemia in non-insulin-dependent diabetes mellitus. J Clin Invest 93:2562-2571

54. Segel SA, Paramore DS, Cryer PE (2002) Hypoglycemiaassociated autonomic failure in advanced type 2 diabetes. Diabetes 51:724-733

55. Berger B, Stenström G, Sundkvist G (2000) Random Cpeptide in the classification of diabetes. Scand J Lab Clin Invest 60:687-694

56. Cryer PE, Childs BP (2002) Negotiating the barrier of hypoglycemia in diabetes. Diabetes Spectrum 15:20-27

57. The Diabetes Control and Complications Trial Research Group (1991) Epidemiology of severe hypoglycemia in the Diabetes Control and Complications Trial. Am J Med 90:450-459

58. Mühlhauser I, Overmann H, Bender R, Bott U, Berger M (1997) Risk factors for severe hypoglycaemia in adult patients with type 1 diabetes - a prospective population based study. Diabetologia 41:1274-1282

59. Bernard C (1957) An Introduction to the Study of Experimental Medicine (first published in 1865, translated by $\mathrm{H}$. C. Green, Macmillan and Co. 1927) Dover Publications, New York, p 89 